\title{
Burning Issues: A Case-based Approach to Integrating a Multitude of Ecological \& Conservation Biology Concepts
}

\author{
John S. Peters \\ College of Charleston, Biology, 66 George St, Charleston SC 29424 USA \\ (PetersJ@cofc.edu)
}

\begin{abstract}
Constructivist learning theory teaches us that our students are active constructors of knowledge. They do not come to our biology classes as blank slates, rather they come with all kinds of ideas about the natural world, many of which they internalize from cultural memes and popular media. Depictions of forest fires in the news, like the recent Camp Fire that destroyed Paradise CA, send powerful messages to our students about forest ecosystems, fires, and our own relations to these ecosystems. This workshop introduced a case study, which challenges and helps students overcome misconceptions they have about forests and fire. The case study explores ecological concepts such as keystone species, trophic cascades, succession, competition, disturbance and biodiversity in the context of how human developments impact some forest ecosystems. The workshop takes you on a virtual field trip to what once was the largest forest ecosystem (60-90 million acres) in all of North America that was dominated by a single tree species. You will also explore how to modify SimBio's popular Intermediate Disturbance Hypothesis lab simulation from a more verification-style lab into an inquiry-based exploration, in which students use the findings from their own experiment in order to understand the role that periodic disturbances have on biodiversity, integrity and ecosystem services.
\end{abstract}

Keywords: case study, forest ecosystems, fire disturbance, SimBioTM Intermediate Disturbance Hypothesis

\section{Mission, Review Process \& Disclaimer}

The Association for Biology Laboratory Education (ABLE) was founded in 1979 to promote information exchange among university and college educators actively concerned with teaching biology in a laboratory setting. The focus of ABLE is to improve the undergraduate biology laboratory experience by promoting the development and dissemination of interesting, innovative, and reliable laboratory exercises. For more information about ABLE, please visit http://www.ableweb.org/.

Advances in Biology Laboratory Education is the peer-reviewed publication of the conference of the Association for Biology Laboratory Education. Published articles and extended abstracts are evaluated and selected by a committee prior to presentation at the conference, peer-reviewed by participants at the conference, and edited by members of the ABLE Editorial Board. Published abstracts are evaluated and selected by a committee prior to presentation at the conference.

\section{Citing This Article}

Peters JS. 2020. Burning issues: a case-based approach to integrating a multitude of ecological \& conservation biology concepts. Article 48 In: McMahon K, editor. Advances in biology laboratory education. Volume 41. Publication of the 41st Conference of the Association for Biology Laboratory Education (ABLE). https://doi.org/10.37590/able.v41.abs48

Compilation (C) 2020 by the Association for Biology Laboratory Education, ISBN 1-890444-17-0. All rights reserved. No part of this publication may be reproduced, stored in a retrieval system, or transmitted, in any form or by any means, electronic, mechanical, photocopying, recording, or otherwise, without the prior written permission of the copyright owner.

ABLE strongly encourages individuals to use the exercises in this volume in their teaching program. If this exercise is used solely at one's own institution with no intent for profit, it is excluded from the preceding copyright restriction, unless otherwise noted on the copyright notice of the individual chapter in this volume. Proper credit to this publication must be included in your laboratory outline for each use; a sample citation is given above. 